\title{
The Effects of Stacking Sequence Layers of Hybrid Composite Materials in Energy Absorption under the High Velocity Ballistic Impact Conditions: An Experimental Investigation
}

\author{
Elias Randjbaran*, Rizal Zahari, Dayang Laila Majid, Nawal Aswan Abdul Jalil, Ramin Vaghei and Ramin Ahmadi \\ Faculty of Engineering, Universiti Putra Malaysia, 43400 UPM Serdang, Selangor Darul Ehsan, Malaysia
}

\begin{abstract}
In the current study, the effects of stacking sequence layers of hybrid composite materials on ballistic energy absorption, which were fabricated from Kevlar, carbon, glass fibres, and resin have been experimentally investigated at the high velocity ballistic impact conditions. All the samples have equal mass, shape, and density, nevertheless, they have different stacking sequence layers. After running the ballistic test in the same conditions, the final velocities of the bullets showed that how much energy absorbed by the samples. The energy absorption of each sample through the ballistic impact has been calculated, accordingly, the decent ballistic impact resistance materials could be found by conducting the test. This paper can be further studied in order to characterize the material properties.
\end{abstract}

Keywords: Ballistic impact; Hybrid composite; Stacking sequence; Energy absorption

\section{Introduction}

Progressions in the use of hybrid composite materials for the structure of aircraft and auto-mobile industries have risen considerably over the last decade. This has been driven by the need for improved performance requirements in terms of stealth, payload, range, stability and at the same time, a reduction in costs in terms of maintenance, operation, and construction. Much experience in the use of hybrid composites in the aerospace industries has been achieved from the design of composite aeroplanes, which were designed using high stiffness requirements and not for all the parts of the current body of aeroplanes being planned. The stiffness of composites can be determined equitably accurately using the particular tests and material properties from standard material characterization tests. However, with more demanding requirements this has changed and the minimization of damage is something that is now required in order to satisfy higherperformance demands. This is not as simple as optimizing the elastic stiffness of the structure due to the complex damage modes that can occur in hybrid composites. This is particularly true under high velocity ballistic impact scenarios [1].

Carbon, glass, and Kevlar fibre hybrid composites are susceptible to accidental from low to high-energy impacts of such hazards as dropped tools during maintenance, runway debris, hail-stones and sandstorm. These impacts can bring about considerable strength reduction, and the localized damage is potentially a source of mechanical weakness, particularly under the mechanical applications [2-4].

Furthermore, the damage consequent upon a minor impact can grow to large size under the mechanical applications. The nature of the impact damage in hybrid composite laminates ranges from surface damage and subsurface damage to complete penetration, depending upon the impact loading conditions. Generally, under the ballistic impact, damage obtains only in constant plies of a laminate, resulting in so-called part through-the thickness damage. This sort of damage is of a complicated form, consisting of fluctuating amounts of matrix cracks, fibre cracks, and de-lamination. The complexity of the damage makes it difficult to assess the precise mechanisms controlling strength reduction. Among these modes of impact damage, delamination has the most detrimental effects on laminate stiffness and strength, and has received a considerable amount of attention [5-9]. High velocity impact involves projectiles moving at higher velocities such that the local target materials behave like fluids, and the stress induced by the impact is many times the material strength. The goal for this classification is the energy transfer in the middle projectile and target; energy waste and damage propagation mechanisms withstand extreme transfigured as the velocity of the projectile changes. One of the possible ways of magnifying the ballistic limit is to employ textile composites. The kinetic energy of the projectile once impacted into the target is scattered and absorbed in various lanes by the target. The main energy-absorbing mechanisms throughout the ballistic impact are including: kinetic energy absorbed by the moving bullet on the back face of the target, energy absorbed due to tensile failure of the primary fibers' layer then energy absorbed due to the elastic de-formation of the secondary fibers' layer, energy absorbed due to matrix cracking and delamination and frictional energy absorbed in the course of penetration. At high velocity or ballistic impact, the response of the structural element is governed by the local behaviour of the material in the region of the impacted zone; the impact response of the element is generally independent of its assist conditions. The contact cycle of the impact or is smaller than the time cycle of the lowest vibration mode of the structure. Hyper impact involves projectiles moving at extremely high velocities such as the local target materials behave like fluids, and the stress induced by the impact is many times the material strength [10].

Sultan et al. [9] mentioned that as the plate specimen thickness continued to increase, the damage on the lower skin decreased so little which could not be seen. Moreover, as the plate thickness increased,

*Corresponding author: Elias Randjbaran, Faculty of Engineering, Universit Putra Malaysia, 43400 UPM Serdang, Selangor Darul Ehsan, Malaysia, Tel: +440-745-2203616; Fax: +44-0-844-7749975; E-mail: Elias@gmx.co.uk

Received August 15, 2013; Accepted October 08, 2013; Published October 15 2013

Citation: Randjbaran E, Zahari R, Majid DL, Jalil NAA, Vaghei R, et al. (2013) The Effects of Stacking Sequence Layers of Hybrid Composite Materials in Energy Absorption under the High Velocity Ballistic Impact Conditions: An Experimental Investigation. J Material Sci Eng 2: 130. doi:10.4172/2169-0022.1000130

Copyright: (C) 2013 Randjbaran E, et al. This is an open-access article distributed under the terms of the Creative Commons Attribution License, which permits unrestricted use, distribution, and reproduction in any medium, provided the original author and source are credited. 
Citation: Randjbaran E, Zahari R, Majid DL, Jalil NAA, Vaghei R, et al. (2013) The Effects of Stacking Sequence Layers of Hybrid Composite Materials in Energy Absorption under the High Velocity Ballistic Impact Conditions: An Experimental Investigation. J Material Sci Eng 2: 130. doi:10.4172/2169-0022.1000130

Page 2 of 8

the maximum impact load and impact energy increased relatively. Impact damage was in the form of perforation, fibre breakage and matrix cracking. In current study the effects of stacking sequence layers of hybrid composite materials in energy absorption under the high velocity ballistic has been investigated. Impact specimens in terms of composite structures consisting of Kevlar, glass, carbon fibre, and epoxy layers with different sequences were fabricated via hand-lay-up method.

\section{Manufacturing Procedure}

\section{Materials}

Figure 1 shows the three types of fibres, including glass, carbon, and Kevlar were used in fabricating the specimens. Table 1 illustrates the mechanical properties comprising strength, failure strain, and Young's Modulus of carbon, glass, and Kevlar fibres [11]. The Kevlar fabric used in all composite target constructions was plain-woven Hexcel Aramid (poly-paraphenylene terephthalamide), high- performance fabric Style 706 (Kevlar KM-2, 600 denier) with a real density of $180 \mathrm{~g} / \mathrm{m}^{2}$. Table 2 illustrates the mechanical properties including flexural strength, hardness, adhesive strength, compressive modulus, tensile strength, and impact strength of the liquid epoxy resin and hardener. Room temperature curing and the ratios of 50 parts epoxy resin (EPOKUKDO YD-128) to 50 hardener (Polyamide - Domide (A.V: 350)) by weight being cured after seven days at $20^{\circ} \mathrm{C}$ [12].

Table 3 illustrates the ordering and sequence of fibres plies in each hybrid composite materials. As mentioned in the literature review, when loads are parallel to the fibres $\left(0^{\circ}\right)$, the ply is much stronger and stiffer than whereas loads are transverse $\left(90^{\circ}\right)$ to the fibre direction. Therefore, the ply orientation is $\left(0^{\circ}\right)$, the thickness of all is $1.78 \mathrm{~mm}$, and the density of all the Hybrids is about $1.7 \mathrm{~g} / \mathrm{cm}^{3}$.

\section{Experimental testing procedure}

The specimens were produced by hand lay-up method. The experimental set-up was according to guidelines given in the NIJ Standard 0108.01 [10], shown in Figure 2. Compressed Helium gas used as the working fluid. The air pressure from the compressor was kept constant at $0.6 \times 10^{3} \mathrm{kPa}$ while Helium pressure was increased from $1.4 \times 10^{3} \mathrm{kPa}$ to $4.1 \times 10^{3} \mathrm{kPa}$. However, the gun tunnel can be operated at maximum of $21 \times 10^{3} \mathrm{kPa}$. The air pressure was used to open the Helium gas valve at the gun tunnel barrel after its trigger was pushed. The gun tunnel barrel length is about four-metre measured from the bullet reload section and a test section chamber was placed at the end of the gun tunnel barrel. Test section is made of high strength steel that give out most protection during the experiment. The test section chamber is $600 \times 450 \times 450 \mathrm{~mm}^{3}$, length, height, and width respectively as shown in Figures 3-7 [13-15]. It gives enough space for the bullet to be calibrated and stopped. The trigger for the gun tunnel is the places

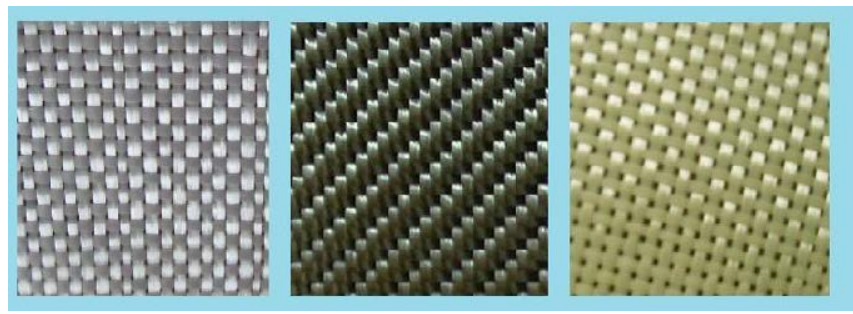

Figure 1: Left to right; Glass, carbon, and Kevlar fiber.

\begin{tabular}{|c|c|c|c|}
\hline Fibre & Strength (GPa) & Failure Strain (\%) & Modulus (GPa) \\
\hline Carbon fibre & 3.8 & 1.76 & 227 \\
\hline E-Glass & 3.5 & 4.7 & 74 \\
\hline $\begin{array}{c}\text { Kevlar@ KM-2, } \\
600 \text { denier }\end{array}$ & 3.4 & 3.55 & 82.6 \\
\hline
\end{tabular}

Table 1: Mechanical properties of the fibers.

\begin{tabular}{|c|c|c|c|c|c|}
\hline $\begin{array}{c}\text { Flexural } \\
\text { Strength } \\
\text { (MPa) }\end{array}$ & $\begin{array}{c}\text { Hardness } \\
\text { (Rockwell) } \\
\text { M Scale }\end{array}$ & $\begin{array}{c}\text { Adhesive strength } \\
\text { (lapshear) } \\
\mathbf{c m}^{2} \text { (Kg/ }\end{array}$ & $\begin{array}{c}\text { Compressive } \\
\text { Modulus } \\
\text { (MPa) }\end{array}$ & $\begin{array}{c}\text { Tensile } \\
\text { Strength } \\
\text { (MPa) }\end{array}$ & $\begin{array}{c}\text { Impact } \\
\text { Strength } \\
\text { (Kg.cm/ } \\
\mathbf{c m}^{2} \text { ) }\end{array}$ \\
\hline 780 & 80 & 65 & 636 & 400 & 2.1 \\
\hline
\end{tabular}

Table 2: Mechanical Properties of the Liquid Epoxy Resin are EPOKUKDO YD128 , and hardener is Polyamide - Domide (A.V: 350 ).

\begin{tabular}{|c|c|c|c|c|}
\hline HYBRID 1 & HYBRID 2 & HYBRID 3 & HYBRID 4 & HYBRID 5 \\
\hline Kevlar & Glass & Kevlar & Glass & Kevlar \\
\hline Carbon & Carbon & Glass & Kevlar & Carbon \\
\hline Glass & Kevlar & Carbon & Carbon & Glass \\
\hline Kevlar & Carbon & Glass & Carbon & Glass \\
\hline Glass & Kevlar & Carbon & Glass & Carbon \\
\hline Carbon & Glass & Kevlar & Kevlar & Kevlar \\
\hline
\end{tabular}

Table 3: The fabricated composite sheets are divided into five groups.

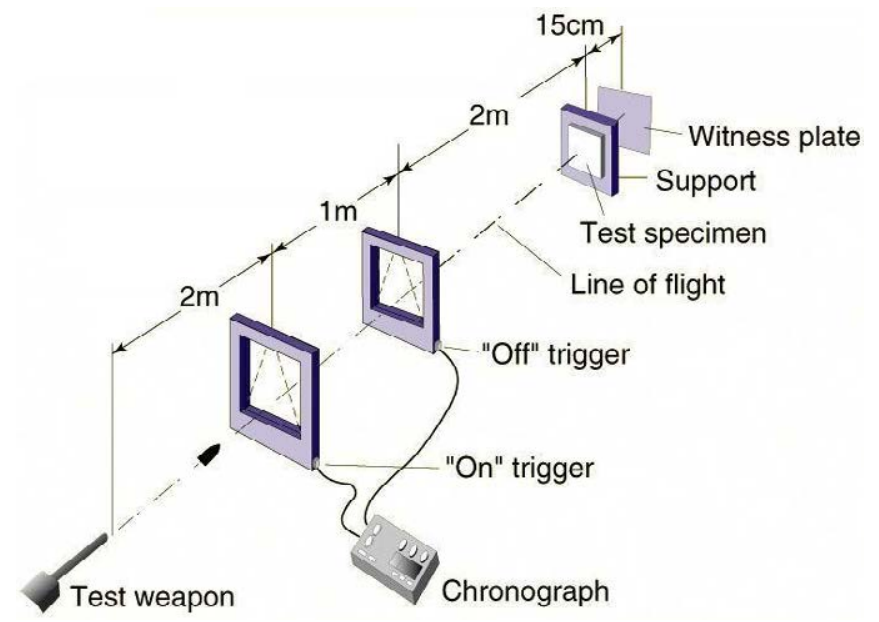

Figure 2: Schematic of ballistic test setup following the NIJ Standard.

near to the bullet reload section where far away from the test section chamber making much safety working area.

Figures 3-7 display the actual gun tunnel used for the experiment. Figure 8 illustrates the bullet travelling. Figure 9 shows the schematic of the mild steel bullet being used in the experiment. Cylindrical bullets were used in the experiment to calibrate the bullet speed by varying Helium gas pressure. Bullet used in the experiment was made of mild steel with $6.75 \mathrm{~g}$ of weight. The length is $13.07 \mathrm{~mm}$ by $8.48 \mathrm{~mm}$ in diameter. It has a smooth cylindrical surface to have minimum friction and drag during its light. Together with that, oil also being used as a tube to the bullet which helps to reduce surface friction contact.

\section{Calculation of velocity}

This invention relates to high-speed cameras and in particular to high-speed cameras having resolution times of less than one-tenth microsecond.

High frame rates are required a sensor with good sensitivity, either a 
Citation: Randjbaran E, Zahari R, Majid DL, Jalil NAA, Vaghei R, et al. (2013) The Effects of Stacking Sequence Layers of Hybrid Composite Materials in Energy Absorption under the High Velocity Ballistic Impact Conditions: An Experimental Investigation. J Material Sci Eng 2: 130. doi:10.4172/2169-0022.1000130

Page 3 of 8

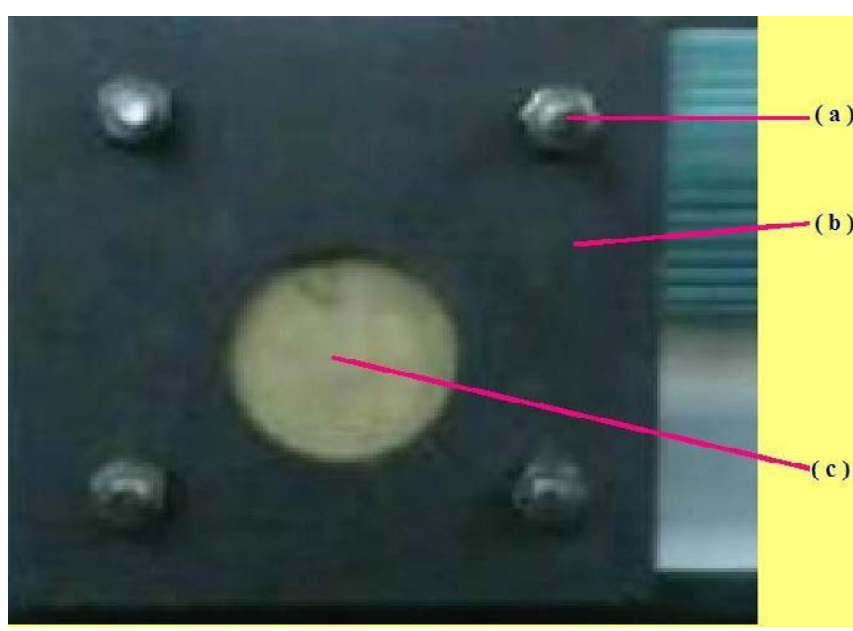

Figure 3: (a) Hexagon Bolts, (b) Steel frame for mounting, and (c) Specimen.

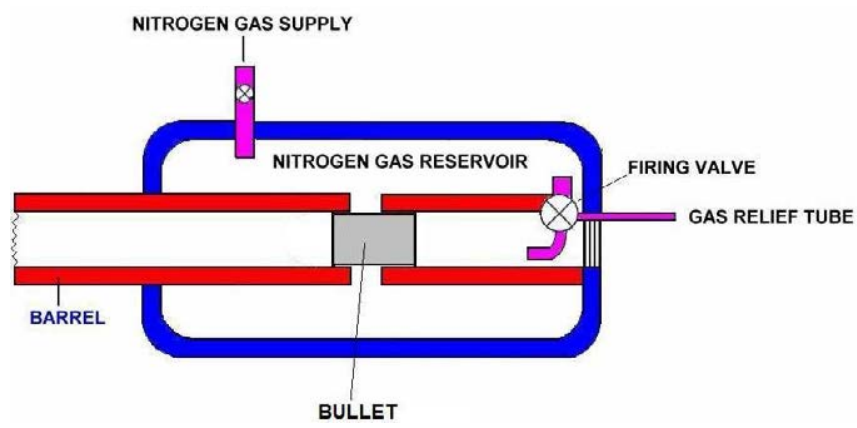

Figure 4: Schematic of gas gun and bullet in the barrel.

very good shuttering system or a very fast strobe light, and also requires some means of capturing successive frames, either with a mechanical device or by moving data off electronic sensors very quickly. In such higher frame rates, it is found that a slight difference in debris cloud formation was captured in the inter-frame of 4 microseconds, which is equivalent to the 250,000 frames per second, and the debris fragment distributions appear to be slightly narrower and thinner at cryogenic temperature.

\section{Calculation of energy}

It is an established fact that absorbed energy by a specimen in ballistic test is a means to quantify impact-penetration resistance. Therefore, the absorbed Kinetic energy of armour-projectile interaction can be linked by equation (1) where are defined as the total Kinetic energy has been absorbed by the specimen, the Kinetic energy of the projectile prior to impact, and the residual kinetic energy after penetrating through the specimen, respectively. From this point, the equation (1) can be further derived into the equations (2) and (3), which are using the classical Physics relationship describing the Kinetic energy of a moving object whereas $\mathrm{mp}$ is the mass of the projectile $\mathrm{V}_{\text {iniatial }}$ and $\mathrm{V}_{\text {final }}$ are the projectile initial and final velocities:

$$
\begin{aligned}
& \mathrm{E}_{\mathrm{abs}}=\mathrm{E}_{\text {initial }}-\mathrm{E}_{\text {final }} \\
& \mathrm{E}_{\text {abs }}=0.5 \mathrm{~m}_{\mathrm{p}} \mathrm{V}_{\text {initial }}^{2}-0.5 \mathrm{~m}_{\mathrm{p}} \mathrm{V}_{\text {final }}^{2} \\
& \mathrm{E}_{\text {abs }}=0.5 \mathrm{~m}_{\mathrm{p}}\left(\mathrm{V}_{\text {initial }}^{2}-\mathrm{V}_{\text {final }}^{2}\right)
\end{aligned}
$$

\section{Results and Discussion}

\section{Ballistic impact testing}

High speed photography and calculating the velocities of the bullets: After fabricating the required number of specimens, a variety of tests were carried out to investigate the behaviour of the various groups of specimens when they were subjected to impact and then under compression. Moreover, the number of experimental runs is fifty.

Figure 10 shows the process of penetration of bullets into the specimens. In addition, Figure 11 and Table 4 illustrate the amount of ejected materials in all the six different types of specimens, include the five Hybrids and the pure carbon fibre are diverse to each other. The amount of ejected materials is evidence for absorbing energy. The percentage average of weight loss is $9.8 \%$, as a consequence Hybrid 1 and Hybrid 5 are above the average and the rest specimens are below average. If the amount of ejected materials becomes increase, the energy absorption becomes decrease. The amount of ejected materials

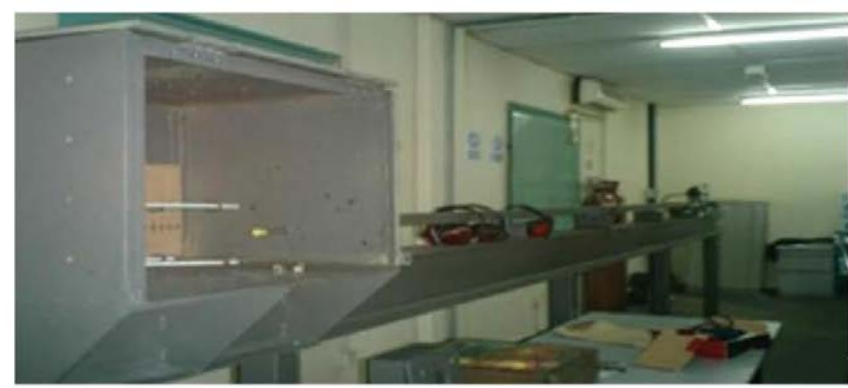

(a)

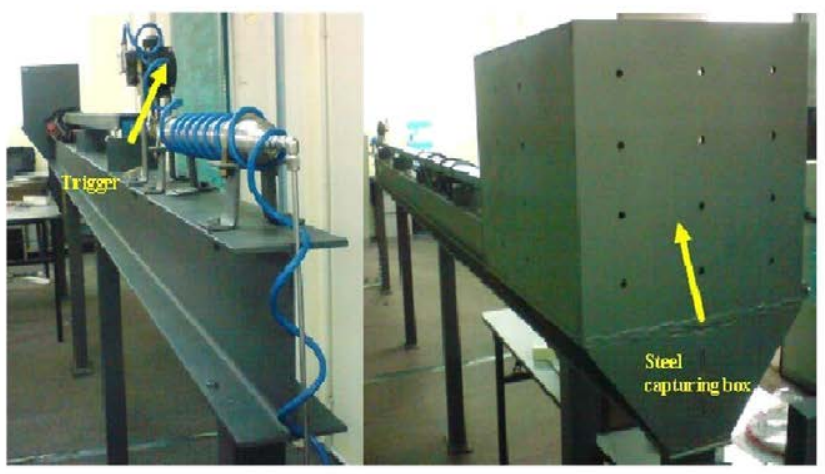

(b)

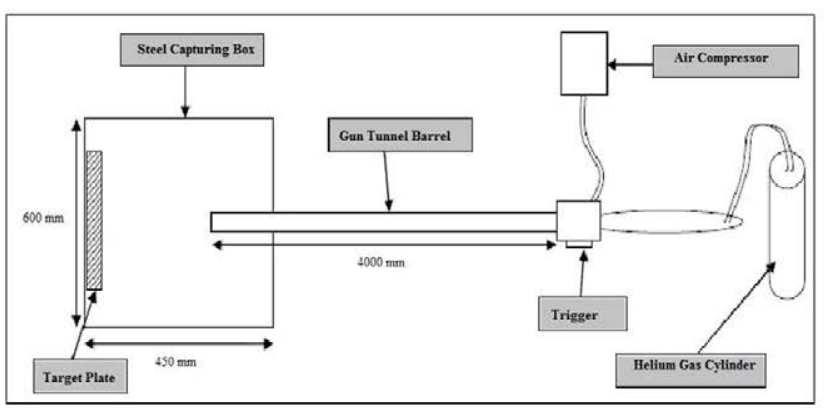

(c)

Figure 5: (a) Gun equipment, (b) Gas gun, and (c) Experimental set-up impact. 
Citation: Randjbaran E, Zahari R, Majid DL, Jalil NAA, Vaghei R, et al. (2013) The Effects of Stacking Sequence Layers of Hybrid Composite Materials in Energy Absorption under the High Velocity Ballistic Impact Conditions: An Experimental Investigation. J Material Sci Eng 2: 130. doi:10.4172/2169-0022.1000130

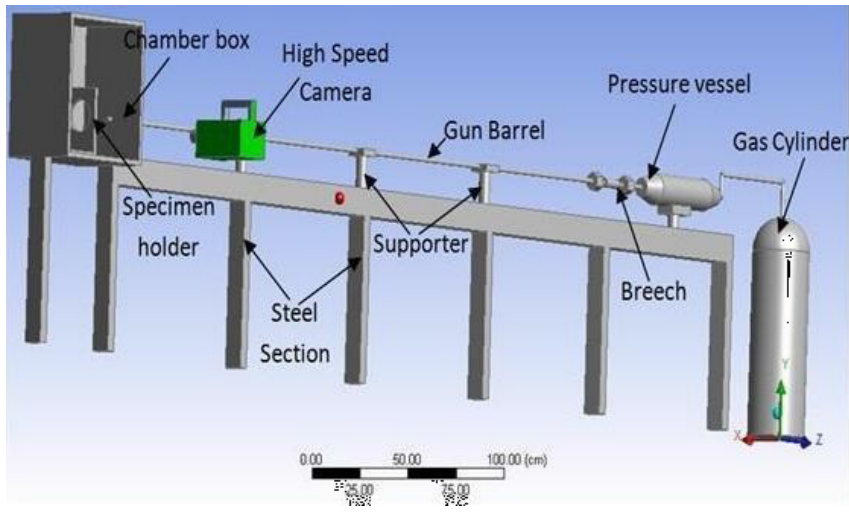

Figure 6: Schematic of Gas gun tunnel instrument for impact test.

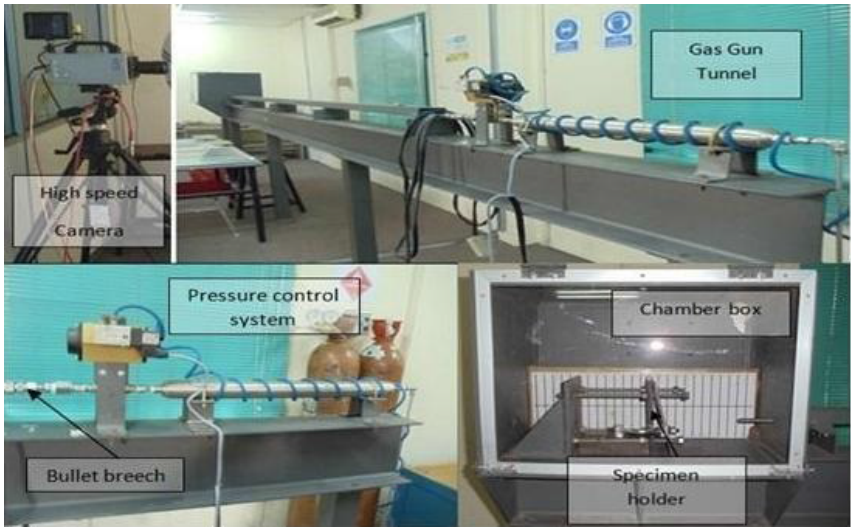

Figure 7: Gas gun tunnel for conducting the ballistic impact test.

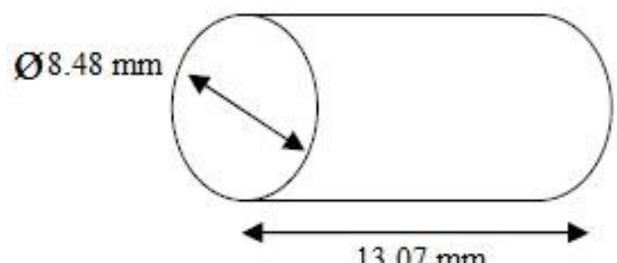

Figure 8: Schematic of the mild steel bullet.

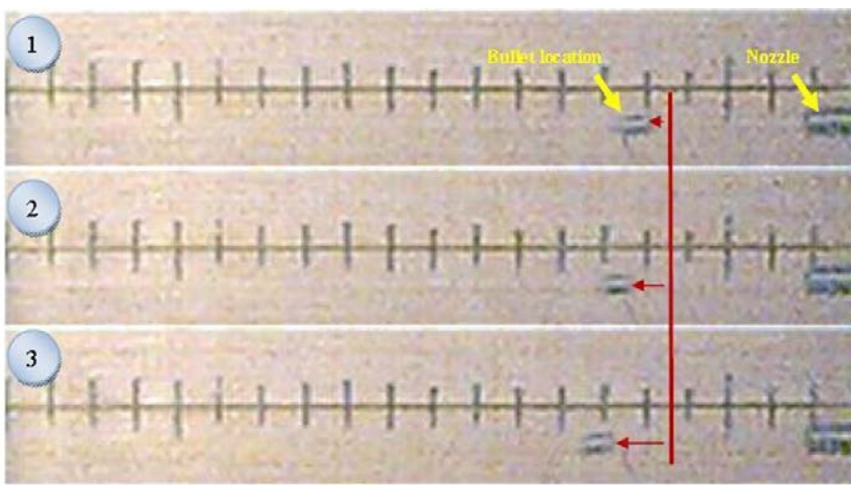

Figure 9: Three frames of snapshots taken via the high speed camera (300 psi $\mathrm{He}$, at 30,000 frames per seconds).

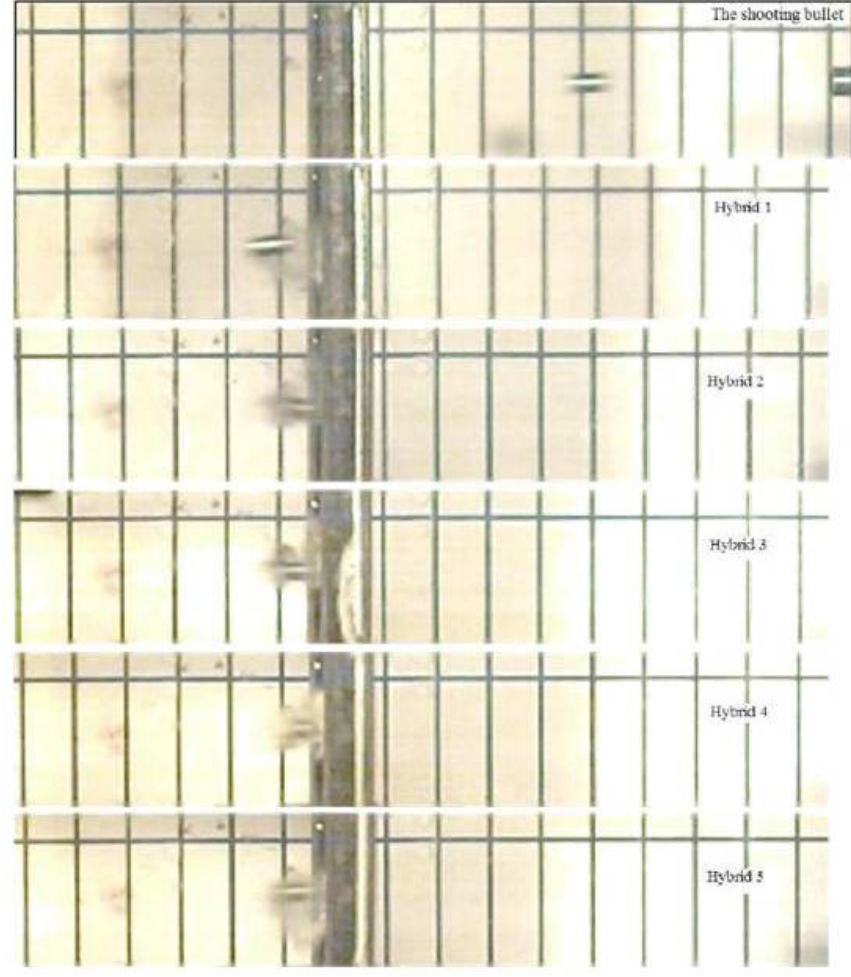

Figure 10: Process of penetration of bullets into the specimens.

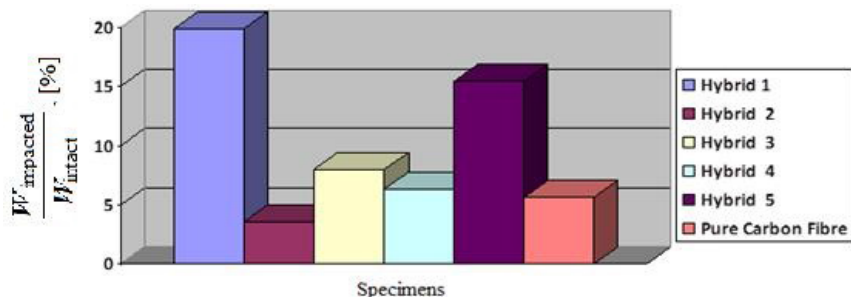

Figure 11: Fraction of the specimen's weight after ballistic impact to intact in percent.

\begin{tabular}{|c|c|c|c|}
\hline Specimen & $\begin{array}{c}\text { Before Ballistic } \\
\text { Impact (g) }\end{array}$ & $\begin{array}{c}\text { After Ballistic } \\
\text { Impact (g) }\end{array}$ & Weight Loss (\%) \\
\hline Hybrid 1 & 30.14 & 25.15 & 19.84 \\
\hline Hybrid 2 & 30.12 & 29.09 & 3.54 \\
\hline Hybrid 3 & 30.11 & 27.88 & 8 \\
\hline Hybrid 4 & 30.17 & 28.38 & 6.31 \\
\hline Hybrid 5 & 30.16 & 26.12 & 15.47 \\
\hline Pure Carbon Fibre & 20.13 & 19.06 & 5.61 \\
\hline
\end{tabular}

Table 4: The weights of the specimens before and after the ballistic impact as well as amount of percentage of the weight loss.

is a significant evidence for absorbing energy. If the amount of ejected materials increases, the energy absorption will consequently decrease. Therefore, among the Hybrid composite materials, the highest amount of ejected materials belongs to Hybrid 1 with $19.84 \%$, and the lowest belongs to Hybrid 2 with $3.54 \%$.

\section{Post-impact images and calculating the perimeter of impacted} zone

Figure 12 shows all six specimens, including Hybrid 1 to Hybrid 5 
Citation: Randjbaran E, Zahari R, Majid DL, Jalil NAA, Vaghei R, et al. (2013) The Effects of Stacking Sequence Layers of Hybrid Composite Materials in Energy Absorption under the High Velocity Ballistic Impact Conditions: An Experimental Investigation. J Material Sci Eng 2: 130. doi:10.4172/2169-0022.1000130

Page 5 of 8

and pure carbon fibre, after ballistic impact, i.e. post-impact images of damaged specimens' profiles. On the left side, impact-induced damage profile viewed from the front face and on the right side, impact- induced damage profile viewed from the back face. Table 5 and Figure 13 illustrate the approximate values of perimeter of impacted zone in millimeters, which are impacted by the bullets. The close correlation



Figure 12: Post-impact images of damaged specimens' profiles: (a) impact-induced damage profile viewed from the front face and (b) Impact-induced damage profile viewed from the back face. 
Citation: Randjbaran E, Zahari R, Majid DL, Jalil NAA, Vaghei R, et al. (2013) The Effects of Stacking Sequence Layers of Hybrid Composite Materials in Energy Absorption under the High Velocity Ballistic Impact Conditions: An Experimental Investigation. J Material Sci Eng 2: 130. doi:10.4172/2169-0022.1000130

Page 6 of 8

\begin{tabular}{|c|c|c|}
\hline No. & Specimen & Perimeter of impacted zone (mm) \\
\hline 1 & Hybrid 1 & 83.2 \\
\hline 2 & Hybrid 2 & 188.5 \\
\hline 3 & Hybrid 3 & 122.6 \\
\hline 4 & Hybrid 4 & 176.4 \\
\hline 5 & Hybrid 5 & 124.9 \\
\hline
\end{tabular}

Table 5: The approximate values of perimeter of impacted zone in millimeters.

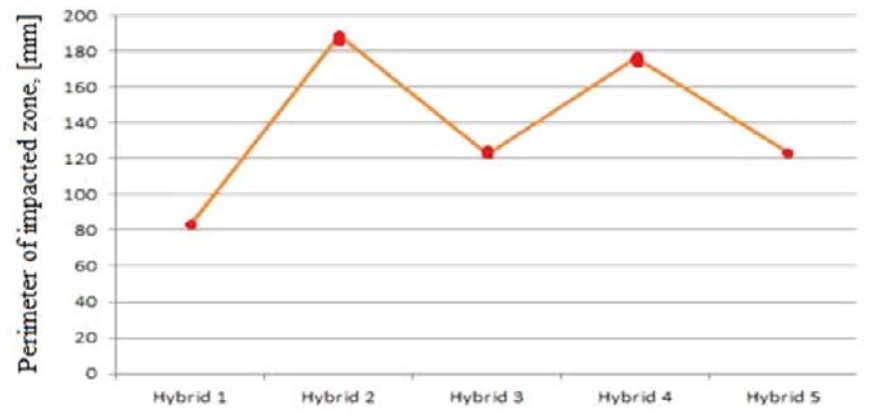

Figure 13: The approximate values of the perimeter of the impacted zone in millimeters, which are impacted-conducted.

between the size of the damage zone varies and the incident kinetic energy of the bullets. If the area is larger, higher amount of ballistic energy will be absorbed.

Hybrid 2 has the largest impact-conducted area with $188.5 \mathrm{~mm}$ and Hybrid 2 has the smallest with $83.2 \mathrm{~mm}$. The impact-conducted areas of Hybrid 2 and Hybrid 4 are approximately closed together and their difference is $12.1 \mathrm{~mm}$. On the other hand, Hybrid 3 and Hybrid 5, with $2.3 \mathrm{~mm}$ difference, nearly are aligned.

Regarding to fundamentals of the relationship between the ballistic energy absorption and the impact-conducted areas, Hybrid 2 can absorb the maximum amount of ballistic energy absorption and Hybrid 1 can absorb the minimum. This means that the ratio of the maximum and minimum of the perimeter of the impacted zone, which are impact-conducted, is about $44.14 \%$.

Table 6 illustrates a set of experimental data in relation to the sorts of changes, which are the manifestation of the amount of absorbed ballistic energy (in a Joul scale unit) of each of the specimens according to final velocities of each bullet (in meter per second) at $182 \mathrm{~m} / \mathrm{s}$ as an initial velocity. In general, there is some variation trends unveiled throughout the figure of the information.

Turning to the details, it can be demonstrated that in Hybrid 2, the minimum final velocity is $4.47 \mathrm{~m} / \mathrm{s}$, and maximum final velocity, among the Hybrid specimens, is in Hybrid $1(14.36 \mathrm{~m} / \mathrm{s})$. Furthermore, in Hybrid 2, the maximum energy could be absorbed (95.17 J), among the Hybrid specimens, the minimum of absorbed energy in Hybrid 1 (94.36 J).

Figure 14 shows the final velocities of the bullets in 6 types of specimens, while the initial velocity is $182 \mathrm{~m} / \mathrm{s}$. Hybrid 2 demonstrated the reduction of the velocities of the bullets less than the other specimens. Among the Hybrid specimens, the final velocities of Hybrid 2, Hybrid 3, Hybrid 4, and Hybrid 5 are although close to each other, however, they are not united, and the difference among them is 4.29 $\mathrm{m} / \mathrm{s}$. Furthermore, Hybrid 2 and Hybrid 4 are approximately at the level and the difference between them is $0.81 \mathrm{~m} / \mathrm{s}$. Likewise, Hybrid 3 is comparatively at the level with Hybrid 5 and the difference between them is $0.55 \mathrm{~m} / \mathrm{s}$. Additionally the difference between the maximum and minimum final velocities is $12.51 \mathrm{~m} / \mathrm{s}$.

\section{Calculating the energy absorption upon the ballistic impact}

Figure 15 and Figure 16 show the changes in ballistic impact energy absorption of Hybrid 1 to Hybrid 5 and the pure Carbon fibre at 182 $\mathrm{m} / \mathrm{s}$ as an initial velocity.

The highest concentration of energy absorption is ranging around 95 joules, from a maximum of $95.17 \mathrm{~J}$ for a minimum of $95.01 \mathrm{~J}$, such as Hybrid 2 (95.17 J), Hybrid 4 (95.15 J), Hybrid 5 (95.04 J), and Hybrid 3 (95.01 J). The amount of energy absorption of Hybrid 2 and Hybrid 4 are close to each other, also the difference between both of them is 0.02 J. Another pair of Hybrids, which have approximately similar energy

\begin{tabular}{|c|c|c|}
\hline Specimen & Final Velocity $\mathbf{( m / s )}$ & Ballistic Energy Absorption (J) \\
\hline Hybrid 1 & 14.36 & 94.36 \\
\hline Hybrid 2 & 4.47 & 95.17 \\
\hline Hybrid 3 & 8.76 & 95.01 \\
\hline Hybrid 4 & 5.28 & 95.15 \\
\hline Hybrid 5 & 8.21 & 95.04 \\
\hline Carbon & 26.87 & 93.16 \\
\hline
\end{tabular}

*Initial Velocity is $182 \mathrm{~m} / \mathrm{s}$

Table 6: Final velocity and energy absorption of the six types of specimens at 182 $\mathrm{m} / \mathrm{s}$ as the initial velocity.

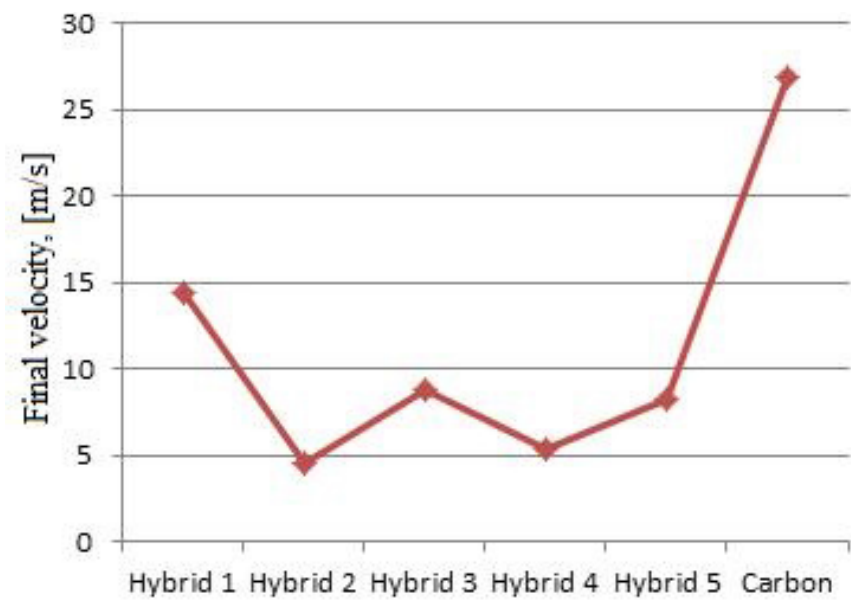

Figure 14: Final velocities of the bullets in six types of specimens.

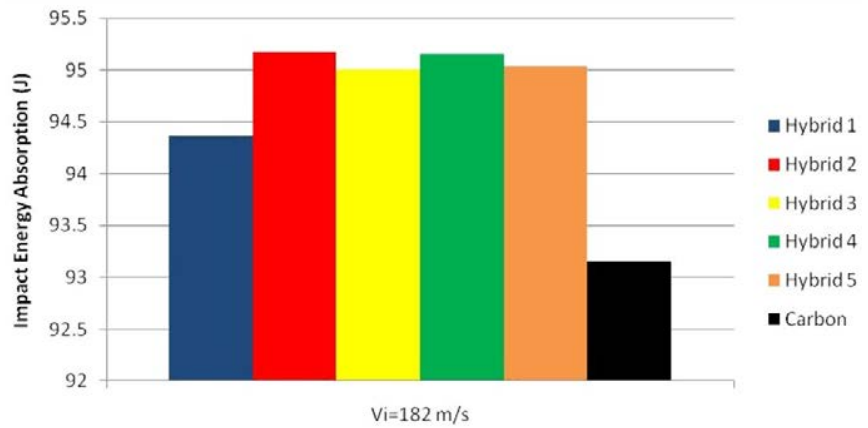

Figure 15: Comparing the amount of energy absorption in six specimens of $182 \mathrm{~m} / \mathrm{s}$ as the initial velocity. 
Citation: Randjbaran E, Zahari R, Majid DL, Jalil NAA, Vaghei R, et al. (2013) The Effects of Stacking Sequence Layers of Hybrid Composite Materials in Energy Absorption under the High Velocity Ballistic Impact Conditions: An Experimental Investigation. J Material Sci Eng 2: 130. doi:10.4172/2169-0022.1000130

Page 7 of 8

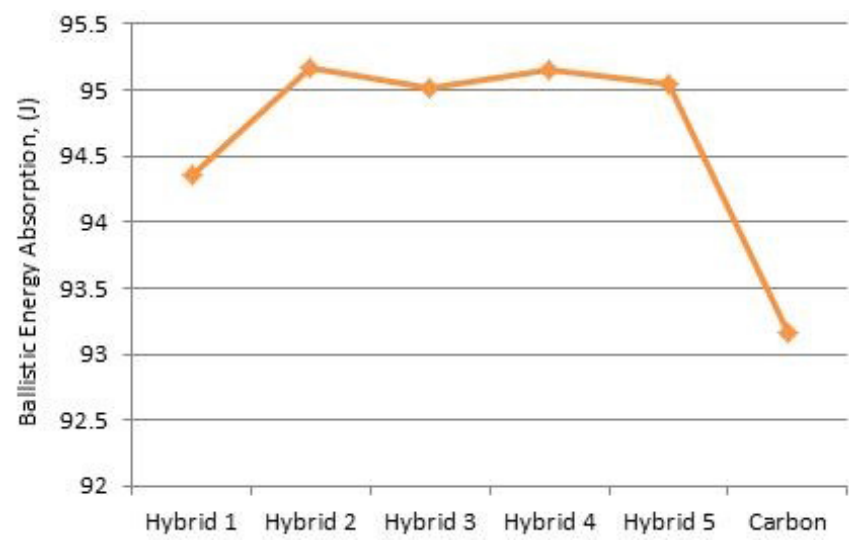

Figure 16: The varieties of final velocities of the bullets in six specimens.

absorptions, is Hybrid 3 and Hybrid 5, the narrow difference between them is $0.03 \mathrm{~J}$.

Hybrid 2 has the maximum ballistic impact energy absorption, in contrast, Hybrid 1 (94.36 J) possesses the minimum ballistic impact energy absorption. And then the disparity between the maximum and minimum ballistic impact energy absorption is $0.81 \mathrm{~J}$.

Figure 17 shows the relationship between that the amounts of ballistic impact energy absorption and the final velocities of the bullets, when the initial velocity of the bullets is 182 meter per second. X-axis indicates the final velocity in meter per hour and Y-axis indicates the amounts of ballistic impact energy absorption in joules. Six different types of specimens, including Hybrid 1 to Hybrid 5 and the pure carbon fibre, have been investigated by conducting the impact test. The most desirable specimen should follow these characteristics: first, reduce the final velocities of the bullets to its lowest level. Second, should have absorbed the highest rate of ballistic impact energy.

Hybrid 2 and Hybrid 4 demonstrated close behaviour in terms of the final velocity and the energy absorption which the final velocity difference of them is $0.81 \mathrm{~m} / \mathrm{s}$ and the energy absorption difference is $0.02 \mathrm{~J}$. Besides, Hybrid 3 and Hybrid 5 are showing the same close behaviour, which velocity difference of them are $0.55 \mathrm{~m} / \mathrm{s}$ and the difference of energy absorption is $0.03 \mathrm{~J}$.

It can be concluded that the amounts of ballistic impact energy absorption have increased, whereas the final velocities of the bullets have gone down slightly. Among the Hybrids, the strongest is Hybrid 2 and the weakest is Hybrid 1. Furthermore, among all of them, the strongest is Hybrid 2 and the weakest is the pure carbon fibre.

The coefficient of restitution: The Coefficient of Restitution (COR) of striking objects is a fractional value representing the ratio of velocities after and before an impact, taken along the line of the impact. Pairs of objects with COR $=1$ collide elastically, while objects with COR $<1$ collide in elastically. For a $\mathrm{COR}=0$, the objects effectively "stop" during the striking, not bouncing at all. An object (singular) is often described as having a coefficient of restitution as if it were an intrinsic property without reference to a second object. In this case the definition is assumed to be with respect to strikes with a perfectly rigid and elastic object [16].

$\mathrm{COR}=($ Velocity after impact $) /($ Velocity before impact $)$

Table 7 and Figure 18 demonstrates the COR, shown as a percentage, in the six different types of specimens, including Hybrid 1 to Hybrid 5 and the pure carbon fibre. The $\mathrm{X}$-axis indicates the types of the specimens and $\mathrm{Y}$-axis indicates the percentage of the COR.

Hybrid 2 has a minimum COR and Hybrid 1 (among the Hybrids) has a maximum COR. Afterward, the difference between them is $5.43 \%$. An average percentage of the COR is about $4.51 \%$. Hybrid 2, Hybrid 4, and Hybrid 5 are below the average line, consequently, Hybrid 1 and Hybrid 3 are above the average line. Table 8 illustrates the sorting of energy absorption from the maximum to the minimum level.

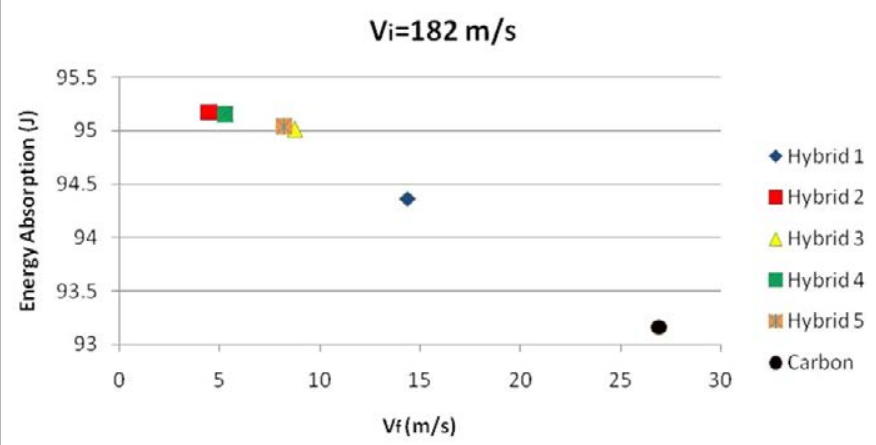

Figure 17: Comparison the energy absorption of six specimens and different final velocities of them at $182 \mathrm{~m} / \mathrm{s}$ as the initial velocity.

\begin{tabular}{|c|c|}
\hline Specimen & COR (\%) \\
\hline Hybrid 1 & 7.89 \\
\hline Hybrid 2 & 2.46 \\
\hline Hybrid 3 & 4.81 \\
\hline Hybrid 4 & 2.9 \\
\hline Hybrid 5 & 4.51 \\
\hline Carbon & 14.76 \\
\hline
\end{tabular}

Table 7: Percentages of the ballistic energy absorption of the specimens.

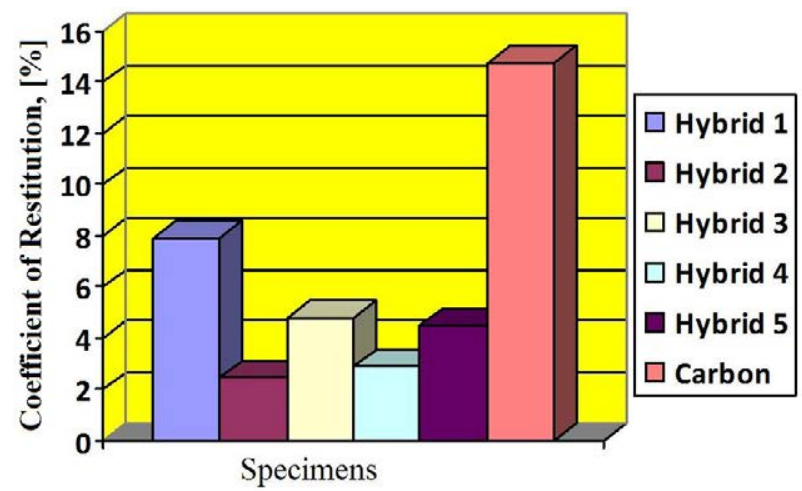

Figure 18: Percentage change of the COR due to the perforation of the specimens at the different final velocities.

\begin{tabular}{|c|c|}
\hline Rank & Specimen \\
\hline 1 & Hybrid 2 \\
\hline 2 & Hybrid 4 \\
\hline 3 & Hybrid 3 \\
\hline 4 & Hybrid 5 \\
\hline 5 & Hybrid 1 \\
\hline 6 & Carbon \\
\hline
\end{tabular}

Table 8: Ranking the specimens according to energy absorption. 
Citation: Randjbaran E, Zahari R, Majid DL, Jalil NAA, Vaghei R, et al. (2013) The Effects of Stacking Sequence Layers of Hybrid Composite Materials in Energy Absorption under the High Velocity Ballistic Impact Conditions: An Experimental Investigation. J Material Sci Eng 2: 130. doi:10.4172/2169-0022.1000130

Page 8 of 8

\section{Conclusions}

The results show, first, the Hybrid 2 has the superlative energy absorption of $95.17 \mathrm{~J}$. Second, it can be concluded that stacking the first layer with glass fibre is better than to use the Kevlar fibre, according to hybrid 2 and hybrid 4 impact specimens with ballistic impact energy absorption of $95.17 \mathrm{~J}$ and $95.15 \mathrm{~J}$ respectively. Moreover, the results indicated that using the combination of carbon and glass is more efficient to use in the central layers. Third, in accordance to Hybrid 1 with ballistic impact energy absorption of $94.36 \mathrm{~J}$, using the carbon fibre is not recommended at the last layer.

\section{References}

1. Ishikawa T, Sugimoto S, Matsushima M, Hayashi Y (1995) Some experimental findings in compression-after-impact (CAI) tests of CF/PEEK (APC-2) and conventional CF/epoxy flat plates. Compos Sci Technol 55: 349-363.

2. Stavropoulos CD, Papanicolaou GC (1997) Effect of thickness on the compressive performance of ballistically impacted carbon fibre reinforced plastic (CFRP) laminates. J Mater Sci 32: 931-936.

3. Jih CJ, Sun CT (1993) Prediction of Delamination in Composite Laminates Subjected to Low Velocity Impact. J Compos Mater 27: 684-701.

4. Pavier MJ, Clarke MP (1995) Experimental techniques for the investigation of the effects of impact damage on carbon-fibre composites. Compos Sci Technol 55: 157-169.

5. Jang BZ, Chen LC, Wang CZ, Lin HT, Zee RH (1989) Impact resistance and energy absorption mechanisms in hybrid composites. Compos Sci Technol 34: 305-335

6. Gweon SY, Bascom WD (1992) Damage in carbon fibre composites due to repetitive low-velocity impact loads. J Mater Sci 27: 2035-2047.
7. Wu E, Shyu K (1993) Response of Composite Laminates to Contact Loads and Relationship to Low-Velocity Impact. J Compos Mater 27: 1443-1464.

8. Naik NK, Shrirao P (2004) Composite structures under ballistic impact. Compos Struct 66: 579-590.

9. Sultan MTH, Basri S, Rafie ASM, Mustapha F, Majid DL, et al. (2011) High Velocity Impact Damage Analysis for Glass Epoxy-Laminated Plates. Adv Mater Res 401: 2318-2328.

10. https://www.ncjrs.gov/pdffiles1/nij/099859.pdf

11. Hernández S, Sket F, González C, LLorca J (2013) Optimization of curing cycle in carbon fiber-reinforced laminates: Void distribution and mechanical properties. Compos Sci Technol 85: 73-82.

12. de Borbón F, Ambrosini D (2013) Dynamic response of composites sandwich plates with carbon nanotubes subjected to blast loading. Composites Part B: Engineering 45: 466-473.

13. Cheeseman BA, Bogetti TA (2003) Ballistic impact into fabric and compliant composite laminates. Compos Struct 61: 161-173.

14. Ramadhan AA, Talib ARA, Rafie ASM, Zahari R (2012) The Behaviour of FibreMetal Laminates under High Velocity Impact Loading with Different Stacking Sequences of Al Alloy. Applied Mechanics and Materials 225: 213-218.

15. Ramadhan AA, Talib ARA, Rafie ASM, Zahari R (2013) High velocity impact response of Kevlar-29/epoxy and 6061-T6 aluminum laminated panels. Mater Design 43: 307-321.

16. Bourrier F, Dorren L, Hungr O (2013) The use of ballistic trajectory and granula flow models in predicting rockfall propagation. Earth Surf Process Landforms 38: $435-440$ 